\title{
Effect of Scrap Melting on the Process Variables in LD Converter Caused by the Change of Operating Conditions*
}

\author{
By Shigeo ASAI** and Iwao MUCHI**
}

\section{Synopsis}

Experimental data on the blowing process of $L D$ converter obtained by the others were plotted on the figure of $c_{m}$ vs. $t_{m}$, and from this figure, it was noted that there were considerable differences between the data for the case where scrap had not been fed into converter and those with feed of scrap, and that the data obtained where all of scrap had not yet been melted varied along the liquidus line of the iron-carbon phase diagram in accordance with the progress of blowing time.

A mathematical model to analyse the behaviors of $c_{m}$ and $t_{m}$ accompanied with the fuctuations of these process variables caused by the changes of operating conditions is developed in this paper.

Furthermore, in order to predict the behaviors of these process variables which may be caused by the melting process of scrap fed into LD converter, the model mentioned above has been interlaced with the mathematical model of LD converter previously proposed by the authors, and numerical calculations have been made on the relations between the temperature of steel bath and the carbon concentration in molten steel under various operating conditions, with the aid of a digital computer. The calculated results of the transitional variations of these two variables have been illustrated on the $T-C$ diagram. From the comparisons of the calculated results with the practical operating results for LD conierter obtained by the other investigators, it may be considered that the model presented in this paper is applicable for the prediction of the behaviors of process variables even in the operations of comparatively high value of scrap ratio.

\section{Introduction}

Since a large quantity of scraps are used for the ordinary blowing process of LD converter, it is desirable to clarify the effect of the melting process of scrap on the transitional variations of process variables such as the temperature and the carbon concentration of molten steel in the converter. However, few works ${ }^{1)-31}$ concerning the process of scrap melting have been presented hitherto, and in these works the distribution of the temperature in scrap and the melting rate of scrap were theoretically analysed under the given conditions of the temperature and the carbon concentration of molten steel.

In this work, a mathematical model is developed by paying one's attention to the temperature and the carbon concentration of molten steel as the important process variables, and the transitional variations of the temperature and the carbon concentration of molten steel which are affected by the melting process of scrap are analysed throughout the blowing time on the basis of this model. Numerical calculations have been conducted with the aid of a digital computer (Data Processing Center, Kyoto University, FACOM 230$60)$.

Then, the mathematical model for the scrap-melting process mentioned above has been interlaced with the model of LD converter previously presented by the authors. ${ }^{4), 5)}$ The results of the numerical calculations concerning the behaviors of process variables obtained from this model have been compared with the data relevant to the blowing process of LD converter obtained by the other investigators ${ }^{6)}$ and also the transient variations of process variables have been given with the changes in the operating conditions such as the scrap ratio, the preheated temperature of scrap, and the carbon concentration of scrap.

\section{Considerations of the Observed Data}

Empirical data obtained by the other investigators $^{7)-14)}$ on the bath temperature and the carbon concentration of molten steel in the blowing process of LD converter or its pilot plants have been plotted on the iron-carbon phase diagram and are illustrated in Fig. 1 (such a figure is called as $\mathcal{T}$-C diagram). In Fig. 1, the points $\left.{ }^{7)}, 8\right)$ shown by smeared marks are the data observed for the case where scrap is not fed into the converter and the other points ${ }^{7,9)-14)}$ are those for the case feeding scrap.

From Fig. 1, it may be found that there are considerable differences between the distributions of the former and the latter points. That is, the former points show a linear relation between the temperature

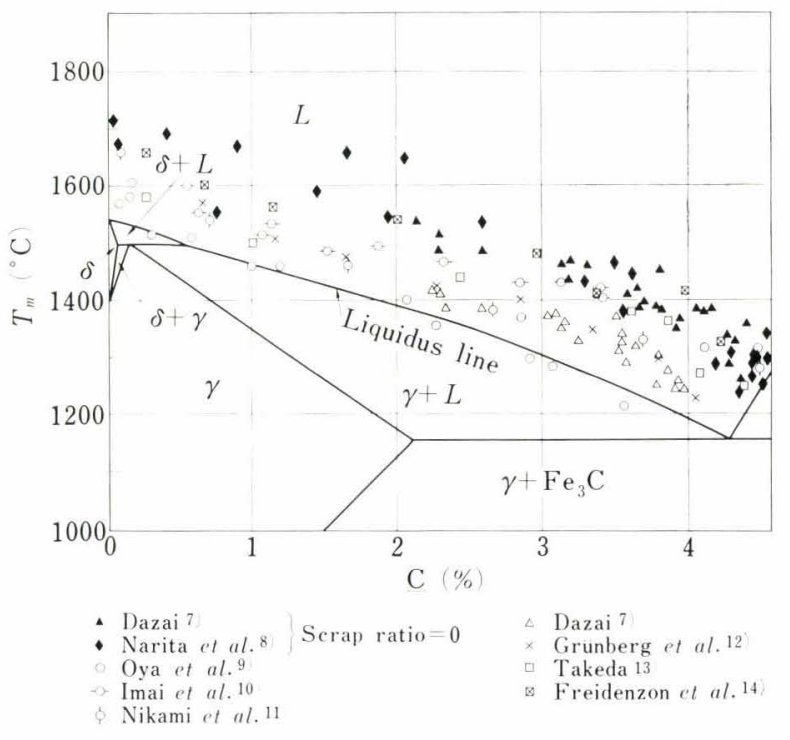

Fig. 1. Iron-carbon phase diagram and data of the bath temperature and the carbon concentration in molten steel obtained under the various operating conditions

\footnotetext{
* Originally published in Tetsu-to-Hagané, 56 (1970), 546, in Japanese. English version received November $10,1970$.

** Department of Iron \& Steel Engineering, Faculty of Engineering, Nagoya University, Furo-cho, Chikusa-ku, Nagoya 464.
} 
and the carbon concentration during the blowing time except for the early period, and the temperature decreases greatly at the beginning. On the other hand, the distributions of the latter points are closely paralled to the liquidus line, and so it may be found that in the case of feeding scrap the variations of the temperature and the carbon concentration are restrained by the liquidus line, although there are some scatterings caused by the differences in the kinds and the amounts of scrap and by those in the operating conditions.

Noting the difference mentioned above on the distributions of the empirical data shown in Fig. 1, the melting process of scrap is analysed and considered in the following sections.

\section{Theoretical Analysis}

Since the melting process of scrap can be considered as a simultaneous heat and mass transfer process, it may be reasonable to treat the process as a distributedparameter system. As this process is a complex one which may be affected by many factors, for instance, the difference in the size and the mass of scrap to be fed or those in the feeding conditions of auxiliary-raw materials, etc., the model of scrap melting has been developed in this work on the basis of a lumped parameter system in order to facilitate the analysis of this process.

Furthermore, this model has been combined with the mathematical model presented by the authors, ${ }^{4), 5}$ ) and the effects of scrap melting on the transitional variations of process variables with the progress of blowing time have been determined by the use of this model.

In this model, it is considered from the assumption of a lumped parameter system that the thermal resistance in scrap may be concentrated only on the surface of scrap. Although various reactions take place in LD converter, only the decarburization reaction is taken into account in this analysis of the melting process of scrap.

The imaginary profiles of the temperature and the carbon concentration in the metal and the scrap sides are illustrated in Fig. 2. Since it is assumed that the thermal resistance is concentrated on the surface of scrap, the temperature distribution in the scrap side is given by a horizontal line. The value of the temperature of scrap calculated from the model mentioned above may be considered as the mean value of the actual temperature in the scrap side.

Now, $\alpha_{1}, \alpha_{2}\left(\mathrm{kcal} / \mathrm{sec}^{\circ} \mathrm{C}\right)$ given in Fig. 2 are the products of the effective surface area of scrap and the heat transfer coefficient in the metal side and one in the scrap side, respectively, and $\beta(\mathrm{kg}(\mathrm{Fe}) / \mathrm{sec})$ is defined as the product of the effective surface area of scrap and the mass transfer coefficient of carbon in the metal side.

The liquidus line of the iron-carbon phase diagram shown in Fig. 1 may be presented approximately by a straight line connecting the melting point of pure iron $\left(0 \% \underline{\mathrm{C}}, 1536^{\circ} \mathrm{C}\right)$ with the eutectic point $(4.26 \% \underline{\mathrm{C}}$, $1153^{\circ} \mathrm{C}$ ), and this line is shown in Fig. 3 as a modified liquidus line and can be expressed as Eq. (1).

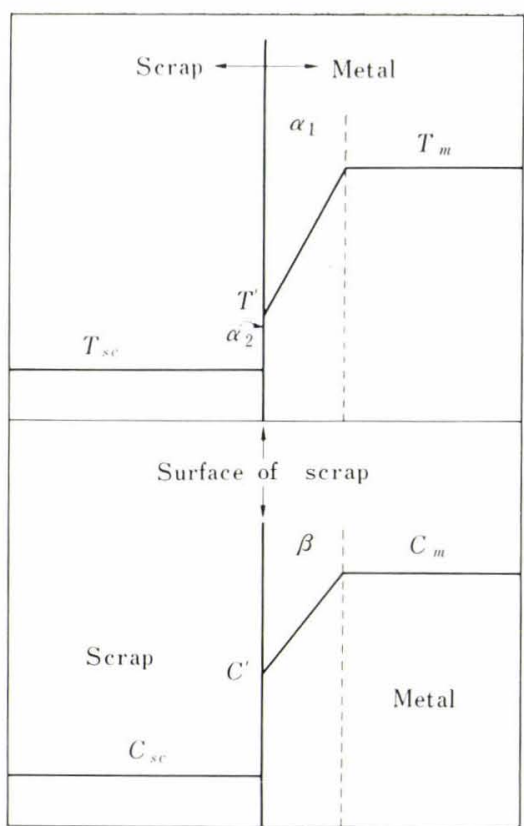

Fig. 2. Diagrammatic representation of gradients of temperature and carbon concentration

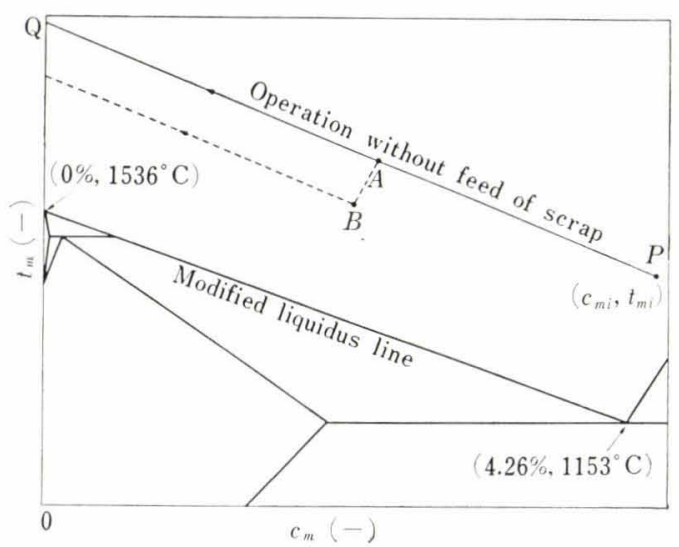

Fig. 3. Modified Fe-C phase diagram and behaviors of the temperature of molten steel and the carbon concentration in steel bath

$$
T=1536-90 C=1536-1.08 \times 10^{5} C \equiv a+b C
$$

Following Eqs. (2), (3), and (4) can be obtained from the heat balances in the scrap and the metal sides, and the material balance of the carbon in molten steel, respectively.

$$
\begin{aligned}
c_{p} d\left(W_{s c} T_{s c}\right) / d \Theta= & \alpha_{2}\left(T^{\prime}-T_{s c}\right)+c_{p} T_{s c} d W_{s c} / d \Theta \ldots \\
c_{p} d\left(W_{m} T_{m}\right) / d \Theta= & \left(-J H_{\mathrm{CO}}\right) \sigma_{1} \cdot S-\alpha_{1}\left(T_{m}-T^{\prime}\right) \\
& -c_{p} T_{s c} d W_{s c} / d \Theta \ldots \ldots \ldots \ldots \ldots \ldots \ldots \ldots \ldots \ldots \ldots \ldots
\end{aligned}
$$

It may be considered that the molten iron fed into LD converter solidifies on the surface of cold scrap at the beginning of blowing period. The directions of heat transfer and of mass transfer of carbon at the solidifying stage of iron mentioned above differ from the directions of these transfers at the melting stage of scrap. There are some differences between the equa- 
tions obtained from the balance at the solidifying stage and those at the melting stage and the former can be represented by Eqs. (2') to (4').

$$
\begin{aligned}
& c_{p} d\left(W_{s c} T_{s c}\right) / d \Theta=\alpha_{2}\left(T^{\prime}-T_{s c}\right)+c_{p} \mathcal{T}_{m}\left(d W_{s c} / d \Theta\right) \ldots(2) \\
& c_{p} d\left(W_{m} T_{m}\right) / d \Theta=\left(-\Delta H_{\mathrm{CO}}\right) \cdot \sigma_{1} \cdot S-\alpha_{1}\left(T_{m}-T^{\prime}\right) \\
& -c_{p} T_{m}\left(d W_{s e} / d \Theta\right) \\
& d\left(W_{m} C_{m}\right) / d \Theta=-\sigma_{1} S-C_{m}\left(d W_{s e} / d \Theta\right)
\end{aligned}
$$

Since the mass of molten steel is increased by the melting of scrap, the relation between the mass of molten steel and that of scrap can be expressed as follows:

$$
d W_{m} / d \Theta=-d W_{s c} / d \Theta
$$

Taking the heat balance and the material balance of carbon on the interfacial surface between molten steel and scrap, the following Eqs. (6) and (7) can be obtained.

$$
\begin{aligned}
\alpha_{1}\left(T_{m}-T^{\prime}\right) & =\alpha_{2}\left(T^{\prime}-T_{s c}\right)+\left(-\Delta H_{\mathrm{Fe}}\right) d W_{s c} / d \Theta . \\
\beta\left(C_{m}-C^{\prime}\right) & =\left(C_{m}-C_{s c}\right) \cdot\left(-d W_{s c} / d \Theta\right) \quad \ldots \ldots \ldots \ldots . .
\end{aligned}
$$

Now, Eqs. (2) to (7) may be presented by the nondimensional equations such as Eqs. (8) to (13), respectively.

$$
\begin{aligned}
d\left(t_{s c} w_{s c}\right) / d \theta & =A_{3} A_{5}\left(t^{\prime}-t_{s c}\right)+t_{s c} d w_{s c} / d \theta \ldots \ldots \ldots \\
d\left(t_{m} w_{m}\right) / d \theta & =A_{1}-A_{3}\left(t_{m}-t^{\prime}\right)-t_{s c} d w_{s c} / d \theta \ldots \ldots \\
d\left(c_{m} w_{m}\right) / d \theta & =-A_{2}-c_{s c} d w_{s c} / d \theta \ldots \ldots \ldots \ldots \ldots \ldots \ldots \ldots \ldots \ldots \ldots \ldots \ldots \ldots \ldots \ldots \ldots \ldots \ldots \ldots \ldots \\
d w_{m} / d \theta & =-d w_{s c} / d \theta \ldots \ldots \ldots \ldots \ldots \ldots \ldots \\
t_{m}-t^{\prime} & =A_{5}\left(t^{\prime}-t_{s c}\right)+1 /\left(A_{3} A_{5}\right) d w_{s c} / d \theta \ldots \\
A_{4}\left(c_{m}-c^{\prime}\right) & =-\left(c_{m}-c_{s c}\right) \cdot d w_{s c} / d \theta \ldots \ldots \ldots \ldots \ldots
\end{aligned}
$$

where,

$$
\begin{gathered}
t \equiv T / T_{m i}, c \equiv C / C_{m i}, w \equiv W / W_{m i}, \theta \equiv \Theta / \Theta_{t}, \\
A_{1} \equiv\left(-\Delta H_{\mathrm{Co}}\right) \sigma_{1} S \Theta_{t} / W_{m i} c_{p} T_{m i}, \\
A_{2} \equiv \sigma_{1} S \Theta_{t} / W_{m i} C_{m i}, A_{3} \equiv \alpha_{1} \Theta_{\imath} / W_{m i} c_{p}, \\
A_{4} \equiv \beta \Theta_{t} / W_{m i}, A_{5} \equiv \alpha_{2} / \alpha_{1}, A_{6} \equiv T_{m i} c_{p} /\left(-\Delta H_{\mathrm{Fe}}\right)
\end{gathered}
$$

Similarly, Eqs. $\left(2^{\prime}\right)$ to $\left(4^{\prime}\right)$ can be described as Eqs. $\left(8^{\prime}\right)$ to $\left(10^{\prime}\right)$.

$$
\begin{aligned}
& d\left(t_{s c} w_{s c}\right) / d \theta=A_{3} A_{5}\left(t^{\prime}-t_{s c}\right)+t_{m} d w_{s c} / d \theta \\
& d\left(t_{m} w_{m}\right) / d \theta=A_{1}-A_{3}\left(t_{m}-t^{\prime}\right)-t_{m} d w_{s c} / d \theta \\
& d\left(c_{m} w_{m}\right) / d \theta=-A_{2}-c_{m} d w_{s c} / d \theta \text {. }
\end{aligned}
$$

Here, it is assumed that the temperature and the carbon concentration on the surface of scrap are identical with the values given by the liquidus line, and this temperature is the same as reported by Mori et $a l .{ }^{2)}$

The surface temperature and the carbon concentration of scrap, $t^{\prime}$ and $c^{\prime}$, can be expressed as Eqs. (14) and (15) by taking $d w_{s c} / d \theta=0$ in Eqs. (12) and (13) which have been derived from the heat balance and the material balance taken on the interface between molten steel and scrap. The factors $t^{\prime}$ and $c^{\prime}$ given by these equations have been derived from the assumptions that molten steel does not solidify and also scrap does not melt, and now these factors are designated at $t_{f}$ and $c_{f}$, respectively.

$$
\begin{aligned}
& t^{\prime}=\left(t_{m}+A_{5} t_{s c}\right) /\left(1+A_{5}\right) \equiv t_{f} \\
& c^{\prime}=c_{m} \equiv c_{f} \quad \ldots \ldots \ldots \ldots \ldots \ldots \ldots \ldots \ldots \ldots
\end{aligned}
$$

If a point $\left(c_{f}, t_{f}\right)$ determined from Eqs. (14) and (15) lies above the liquidus line, $t^{\prime}=A_{7}+A_{8} c^{\prime}$, it may be considered that scrap melts and that molten iron solidifies on the surface of scrap when the point lies below the liquidus line.

where, $\quad A_{7} \equiv a / T_{m i}, A_{8} \equiv b C_{m i} / T_{m i}$

Thus, the melting process of scrap may be divided into the following five cases.

(Case 1) $\quad c_{m}>c_{s e}, t_{f} \geq A_{7}+A_{8} c_{m}$

In this case, the melting process of scrap proceeds, and Eq. (16) can be obtained.

$$
t^{\prime}=A_{7}+A_{8} c^{\prime} \quad\left(0 \leq c^{\prime} \leq 1\right)
$$

where, $c^{\prime}$ and $t^{\prime}$ can be determined from Eqs. (12), (13), and (16) as follows:

$$
\begin{aligned}
& c^{\prime}=\frac{\left(A_{4} / A_{3} A_{6}\right) c_{m}-\left(c_{m}-c_{s c}\right)\left\{\left(1+A_{5}\right) A_{7}-A_{5} t_{s c}-t_{m}\right\}}{A_{4} / A_{3} A_{6}+\left(c_{m}-c_{s c}\right)\left(1+A_{5}\right) A_{8}} \\
& t=\frac{A_{4} A_{7}+A_{4} A_{8} c_{m}+A_{3} A_{6} A_{8}\left(c_{m}-c_{s c}\right)\left(A_{5} t_{s c}+t_{m}\right)}{A_{4}+A_{3} A_{6}\left(c_{m}-c_{s c}\right)\left(1+A_{5}\right) A_{8}}
\end{aligned}
$$$$
\text { (Case 2) } \quad c_{m}>c_{s e}, t_{f}<A_{7}+A_{8} c_{m}
$$

In this case, molten iron solidifies on the surface of scrap. To facilitate the analytical treatment, it is assumed that the solidified iron is immediately transformed into the same composition as one of scrap, that the temperature of the solidified iron becomes equal to that of scrap at once, and that the carbon concentration of molten steel in the neighborhood of the interface between the solidified iron and molten steel does not concentrate by the solidification of molten iron. Then, the relation between the temperature and the carbon concentration may be expressed by Eq. (19).

$$
t^{\prime}=A_{7}+A_{8} c_{m}, \quad c^{\prime}=c_{m}
$$

Furthermore, in this case Eq. (7) or Eq. (13) does not hold and the solidifying rate of molten iron can be determined by Eq. (6).

(Case 3) $\quad c_{m}<c_{s c}, t_{f} \geq A_{7}+A_{8} c_{m}$

In this case, the melting process of scrap proceeds. Such a case may take place when the cold pig iron is fed into converter at the beginning of blowing process or when the carbon concentration is decreased satisfactorily at the last stage of blowing process.

The resistance for the mass transfer does not exist in this case, and the temperature and the carbon concentration on the surface of scrap can be given by Eq. (20).

$$
t^{\prime}=A_{7}+A_{8} c_{s c}, c^{\prime}=c_{s c}
$$

(Case 4)

$$
c_{m}<c_{s c}, t_{f}<A_{7}+A_{8} c_{m}
$$

In this case, molten iron solidifies on the surface of 
scrap or on that of the cold pig iron. This may be found under the conditions in which the cold pig iron is fed into the converter before the beginning of blowing process. The temperature and the carbon concentration on the surface of scrap can be expressed by Eq. (19) given in Case 2.

$$
\text { (Case 5) } \quad w_{s c}=0
$$

This is the case where scrap is not fed into the converter during the blowing process or the period from the melt down of scrap to the end of blowing process.

Solving simultaneously Eqs. (8), (9), (10), and (11) for Cases 1 and 3, Eqs. $\left(8^{\prime}\right),\left(9^{\prime}\right),\left(10^{\prime}\right)$, and (11) for Cases 2 and 4 and Eqs $\left(9^{\prime \prime}\right)$ and $\left(10^{\prime \prime}\right)$ for Case 5, the transitional variations of $t_{m}, c_{m}, t_{s e}$, and $w_{s c}$ can be determined throughout the blowing process.

\section{Calculated Results and Considerations}

1. Case without Feeding of Scrap (Case 5)

In Case 5, Eqs. (9) and (10) can be simplified as Eqs. $\left(9^{\prime \prime}\right)$ and $\left(10^{\prime \prime}\right)$

$$
\begin{aligned}
& w_{m} \cdot d t_{m} / d \theta=A_{1} \\
& w_{m} \cdot d c_{m} / d \theta=-A_{2}
\end{aligned}
$$

The temperature, $t_{m}$, and the carbon concentration, $c_{m}$, of molten steel can be analytically determined as follows:

$$
\begin{aligned}
t_{m} & =t_{m i}+\left(A_{1} / w_{m}\right) \theta . \\
c_{m} & =c_{m i}-\left(A_{2} / w_{m}\right) \theta .
\end{aligned}
$$

Eliminating $\theta$ from Eqs. (21) and (22), the following Eq. (23) can be obtained.

$$
\begin{aligned}
t_{m} & =t_{m i}-\left(A_{1} / A_{2}\right)\left(c_{m}-c_{m i}\right) \\
& =t_{m i}-\left(-\Delta H_{\mathrm{CO}} C_{m i} / c_{p} T_{m i}\right)\left(c_{m}-c_{m i}\right)
\end{aligned}
$$

It may be considered from Eq. (23) that in Case 5 the relations between $t_{m}$ and $c_{m}$ can be described by such a straight line as $\overline{P Q}$ shown in Fig. 3, and that the trajectory of point $B$ on $T-C$ diagram which has been moved to the location from point $A\left(c_{m}, t_{m}\right)$ by some disturbances, e.g. feeding of the auxiliary-raw materials, can be determined also by Eq. (23).

Hence, it may be thought that such trajectory of point $B$ as shown by a dashed line in Fig. 3 becomes parallel to the line $\overline{P Q}$, if the reaction rate of decarburization was not affected by the secondary factors such as slopping. In addition to the decarburization, the oxidation of silicon and the formation of iron oxide actually take place in the converter, and so it is preferable to replace the heat of reaction, $\left(-\Delta H_{\mathrm{Co}}\right)$, in Eq. (3) with the heat of all reactions, $\left(-\Delta H_{\mathrm{al1}}\right)$, including the decarburization, the oxidation of silicon and the formation of iron oxide.

Noting the data for the case of the non-feeding of scrap in Fig. 1, it may be considered that a large change in the bath temperature at the beginning of blowing process is due to the effect of the oxidation of silicon. The slope of the straight line on $T-C$ diagram can be determined by the term of $\left(-\Delta H_{\mathrm{CO}} \cdot C_{m i} / c_{p} \cdot T_{m i}\right)$ in
Eq. (23). Since the blowing rate of oxygen, $S$, and the mass of molten steel, $W_{m}$, are not included in this term, the trajectory on $T-C$ diagram can not be affected by the blowing conditions and the amount of molten steel in the converter, but it is clear from Eqs. (21) and (22) that the moving velocity on the trajectory may be influenced by $S$ and $W_{m}$.

\section{Case with Feeding of Scrap (Cases 1 to 4)}

For Cases 1 to 4, numerical calculations have been conducted on the basis of the data given in Table 1 with the aid of digital computer since analytical solutions cannot be obtained. Dimensionless terms, $A_{3}$, $A_{4}$, and $A_{5}$ shown in Table 1 are unknown parameters and these values have been estimated so as to show a good agreement between the calculated results on $t_{m}$ and $c_{m}$ and these observed data given in Fig. 1. Other data given in Table 1 can be evaluated from the operating conditions and the physical properties of molten steel.

The results calculated by the use of the data given in Table 1 are illustrated in Fig. 4. In Fig. 4 the transitional variations of $t_{s c}, t_{m}, c_{m}$, and $w_{s c}$ are shown as a fuction of the blowing time, $\theta$.

In Fig. 4, Case 2 occurs from the beginning up to about $9 \%$ of the total blowing time and the mass of scrap increases as a result of the solidification of molten iron on the surface of scrap. Since the heat transfer from the molten steel to the surface of scrap takes place remarkably in this period, the increase in $t_{m}$ is hardly found but $t_{s c}$ increases. Then Case 1 follows Case 2 and the melting process of scrap takes place. In this period $t_{m}$ and $t_{s c}$ approach gradually, and Case 1 changes to Case 5 after the completion of the scrap melting.

The calculated results of $c_{m}$ and $t_{m}$ shown in Fig. 4 are represented by a dashed line in Fig. 5 of $T-C$ diagram.

In Fig. 5 the results calculated under the conditions of Table 1 for the case where scrap is not fed into converter are shown by a solid line and those for each case of the blowing conditions of $1.5 \mathrm{~S}$ and $0.5 \mathrm{~S}$ are shown by a two dots-and-dash line and a dot-and-dash line, respectively.

It may be found from Fig. 5 that the curve showing the relations between $c_{m}$ and $t_{m}$ in the case where the melting of scrap is not complete lies almost parallel to

Table 1. Data for numerical calculation

$$
\begin{aligned}
A_{1}= & \left(-J H_{\mathrm{CO}}\right)\left(\sigma_{1} S / W_{m i}\right) \cdot\left(\Theta_{t} / c_{p} T_{m i}\right)=\left(33 \times 10^{3}\right)\left(3.1 \times 10^{-6}\right) \\
& (1200) /(0.17)(1300)=0.55 \\
A_{2}= & \left(\sigma_{1} S / W_{m i}\right) \cdot\left(\Theta_{t} / C_{m i}\right)=\left(3.1 \times 10^{-6}\right)(1200) /(4.3 / 1200)=1 \\
A_{3}= & \left(\alpha_{1} / W_{m i}\right) \cdot\left(\Theta_{t} / c_{p}\right)=\left(0.781 \times 10^{-3}\right)(1200) /(0.17)=5.5 \\
A_{4}= & \left(\beta / W_{m i}\right) \cdot \Theta_{t}=\left(1.25 \times 10^{-3}\right)(1200)=1.5 \\
A_{5}= & \alpha_{2} / \alpha_{1}=0.15 \\
A_{6}= & \left.T_{m i} c_{p} /(-\lrcorner H_{\mathrm{Fe}}\right)=(1300)(0.17) /(-66)=-3.35 \\
A_{7}= & a / T_{m i}=(1536) /(1300)=1.18 \\
A_{8}= & b C_{m i} / T_{m i}=\left(-1.08 \times 10^{5}\right)(4.3 / 1200) /(1300)=-0.298 \\
w_{s c i}= & W_{s c i} / W_{m i}=0.2 \\
t_{s c i}= & T_{s c i} / T_{m i}=(30) /(1300)=0.0231 \\
c_{s c i}= & C_{s c i} / C_{m i}=(0.01 / 1200) /(4.3 / 1200)=0.0023
\end{aligned}
$$




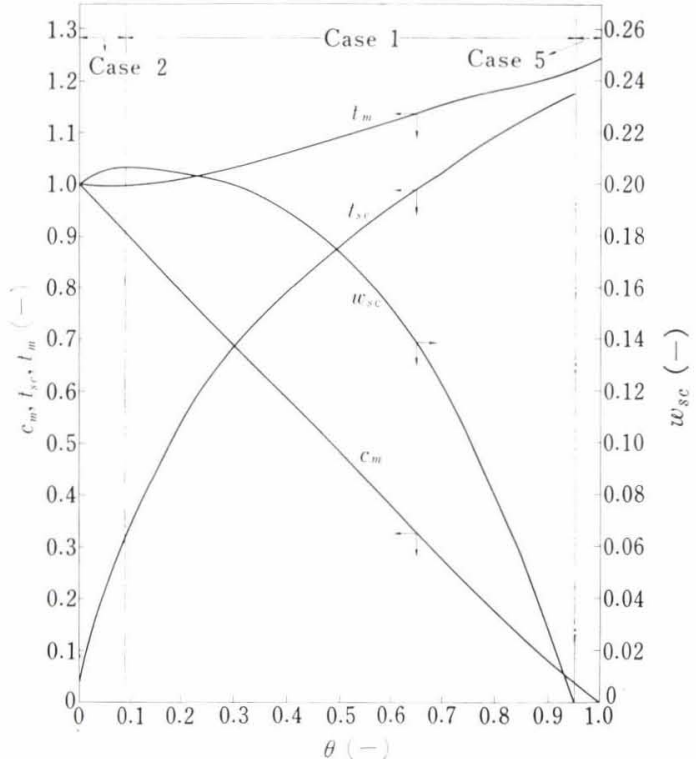

Fig. 4. Calculated results of process variables (scrap temperature: $t_{s c}$, metal temperature: $t_{m}$, carbon concentration: $c_{m}$, mass of scrap: $w_{s c}$ )

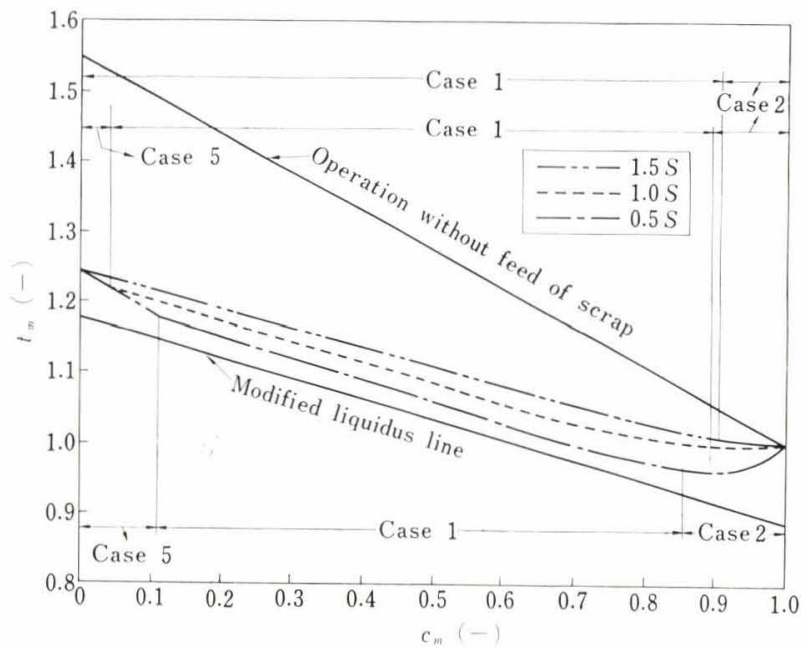

Fig. 5. Calculated results of the temperature of molten steel and the carbon concentration in steel bath under various operating conditions

the liquidus line of the iron-carbon phase diagram during the period of Case 1, and that the effects of such large changes in the values of $S$ as from $1.5 S$ to $0.5 S$ on the variations in the trajectory of the point $\left(c_{m}, t_{m}\right)$ are comparatively small. In the rapid blowing shown by a two dots-and-dash line, Case 1 continues for a long distance and Case 5 does not occur.

\section{Effects of the Fluctuations of $c_{m}$ and $t_{m}$}

Calculated results of the effects of the changes in $c_{m}$ or $t_{m}$ caused by some disturbances in the blowing process (e.g., the feeding of ore and limestone or the carbonaceous materials, etc.) on the transitional variations of the point $\left(c_{m}, t_{m}\right)$ on $T-C$ diagram are illustrated in Figs. 6 and 7. In Fig. 6 the results calculated for the cases where the values of $c_{m}$ are increased or decreased by 0.05 (about $0.2 \% \underline{\mathrm{C}}$ ) and by 0.1 (about $0.4 \% \underline{\text { C) from }} c_{m}=0.5$ (about $2 \% \underline{\text { C) }}$ ) are illustrated.

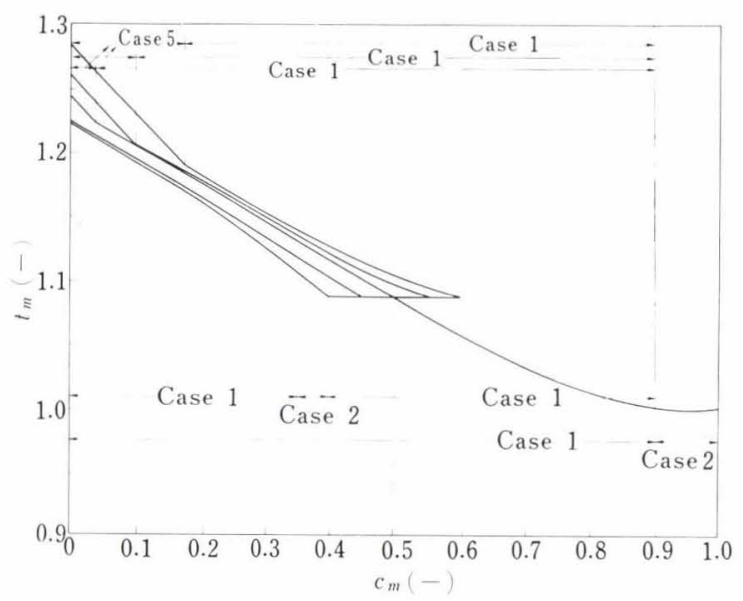

Fig. 6. Variations of $c_{m}$ and $t_{m}$ caused by the fluctuations of the carbon concentration which took place suddenly at $c_{m}=0.5$

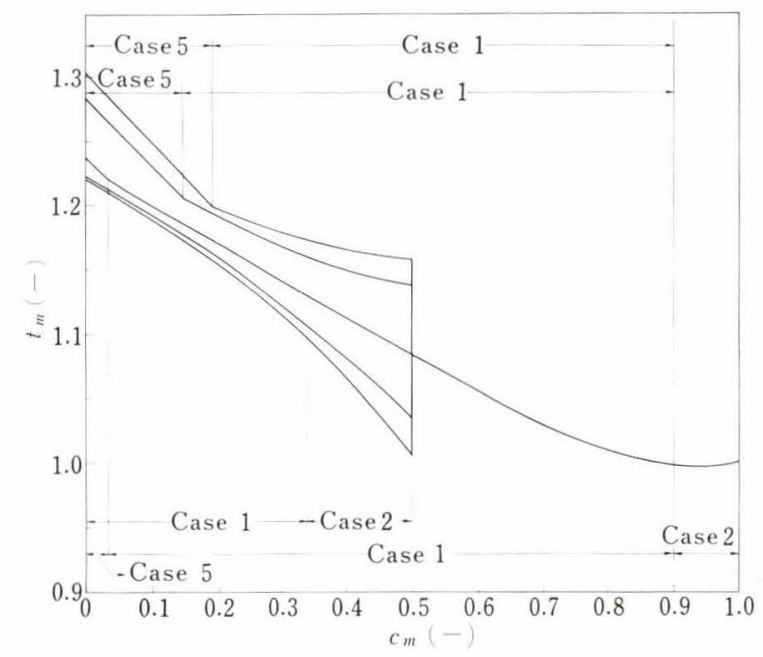

Fig. 7. Variations of $c_{m}$ and $t_{m}$ caused by the fluctuations of steel temperature which took place suddenly at $c_{m}=$ 0.5

It may be found from Fig. 6 that the trajectory of the point $\left(c_{m}, t_{m}\right)$ where the disturbance has been added approaches gradually to one in the case of non-disturbance. As shown in Fig. 6, in the case where the disturbance of the decrease in $c_{m}$ has been added, Case 5 is not taken place up to the end of blowing process and the unmelted scraps remain in the converter. In the case where $c_{m}$ has been increased, if a larger disturbance is added, then Case 1 changes to Case 5 at the higher carbon concentration. After the completion of the scrap melting, the trajectories in Fig. 6 are in parallel with each other as mentioned in the analysis of Case 5. In Fig. 7 the results calculated for the cases where the values of $t_{m}$ have been changed by \pm 0.075 (about $\pm 100^{\circ} \mathrm{C}$ ) and by \pm 0.05 (about $\pm 65^{\circ} \mathrm{C}$ ) from the state of $t_{m}=1.09$ (about $1417^{\circ} \mathrm{C}$ ) at $c_{m}=0.5$ are illustrated. It may be found that the trajectory where the disturbance has been added approaches gradually to the one for the case of non-disturbance, and this approach is the same as in Fig. 6. The fluctuation added in the case where no scrap has been fed 
into the converter (i.e., Case 5) does not disappear and remains as it is up to the end of blowing, but from Figs. 6 and 7 it may be found that as far as the scrap exists in the converter, the added fluctuation decreases gradually with the progress of blowing process.

As mentioned above, scrap has the effect compensating disturbance added during the blowing process and it may be explained qualitatively as follows. When $c_{m}$ and $t_{m}$ have been increased by some disturbances, the driving forces for the heat and mass transfers increase and the scrap becomes easy to melt.

The carbon concentration in molten steel may be diluted on account of the melting process of scrap and the temperature of molten steel may be decreased by the latent heat of melting.

On the other hand, when $c_{m}$ and $t_{m}$ have been decreased by some causes, the scrap becomes difficult to melt and the melting rate of scrap may be decreased. After all, it may be considered that the state where the disturbance has been added shows a tendency to approach to the one where the disturbance is not added.

\section{Effects of the Flow Rate of Oxygen}

To examine the variations of the point $\left(c_{m}, t_{m}\right)$ on $T-C$ diagram when the feeding rate of oxygen has been changed during the blowing process, the trajectories of the point $\left(c_{m}, t_{m}\right)$ obtained for the cases where $S$ was changed from $1.0 S$ to $0.5 S$ and $1.5 S$, respectively, at the point of $c_{m}=0.5$ are illustrated by solid lines in Fig. 8. In both cases, each trajectory on the $T-C$ diagram after the point changed $S$ gradually approaches to each trajectory which is shown by a dotand-dash line for the case of $0.5 \mathrm{~S}$ from the beginning of blowing process and by a two dots-and-dash line for the case of $1.5 \mathrm{~S}$ from the start, respectively.

\section{Effects of the Parameters $\alpha_{1}$ and $\beta$}

The results calculated by the use of data shown in Table 1 for each case where parameter $\alpha_{1}$ has been changed to $1.5 \alpha_{1}$ and $0.5 \alpha_{1}$, respectively, are shown in Fig. 9 by a dotted and a dot-and-dash lines, respectively.

Since the rate of heat transfer from molten steel to scrap decreases with the decrease in the value of $\alpha_{1}$, comparing the values of $t_{m}$ at the same value of $c_{m}$ at large $\alpha_{1}$ and small $\alpha_{1}$ one of $t_{m}$ at the latter becomes high due to the heat accumulated in molten steel. Furthermore, with the decrease in the value of $\alpha_{1}$, the carbon concentration in which Case 2 moves to Case 1 changes to the higher concentration and the one which Case 1 moves to Case 5 to the lower one.

Since the light scrap has larger effective surface area than the heavy scrap and the heat transfer coefficient becomes large for the case of hard blow, the value of $\alpha_{1}$ becomes large for the cases of the light scrap and the hard blow. In such cases as mentioned above, the trajectory of the point $\left(c_{m}, t_{m}\right)$ on $T-C$ diagram approaches to the liquidus line and this behavior is similar to the one for the case of small $S$ shown in Fig. 5 .

The results calculated with the data given in Table 1 for the cases where the value of $\beta$ has been changed $0.5 \beta$ and $1.5 \beta$ are illustrated in Fig. 10 by a dotted and

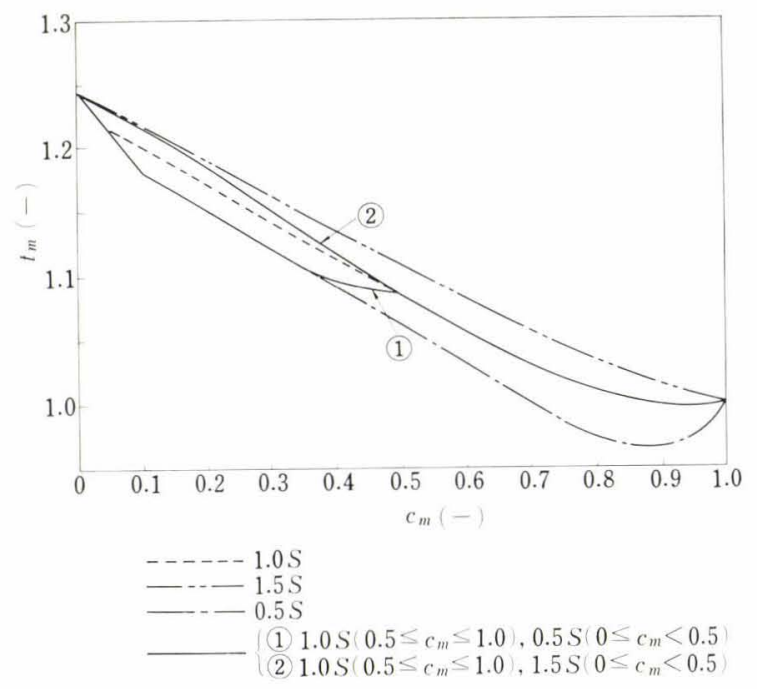

Fig. 8. Cialculated results of $c_{m}$ and $t_{m}$ for the cases where flow rate of absorbed oxygen $S$ was changed $0.5 S$ and $1.5 \mathrm{~S}$, respectively, at $c_{m}=0.5$

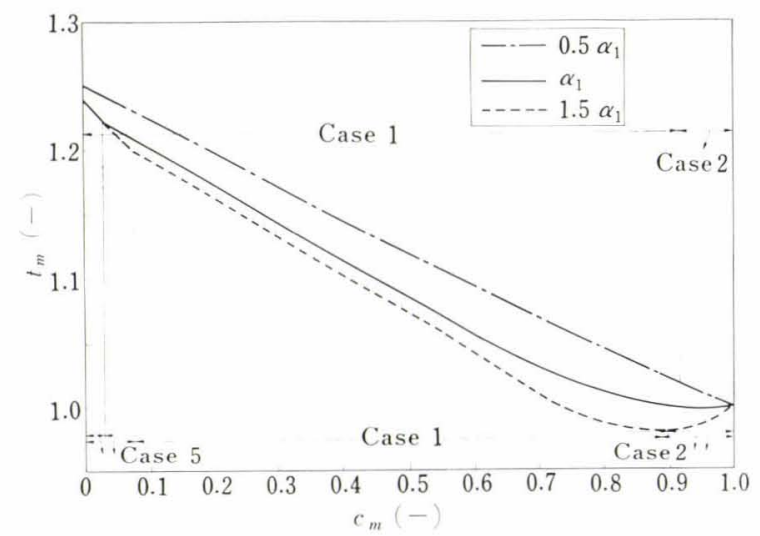

Fig. 9. Calculated results of $c_{m}$ and $t_{m}$ under the various values of $a_{1}$

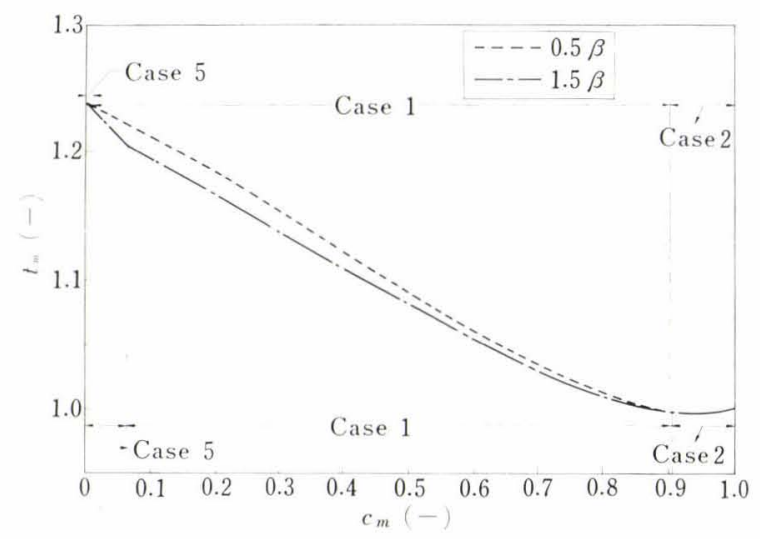

Fig. 10. Calculated results of $c_{m}$ and $t_{m}$ under the various values of $g$

a dot-and-dash lines, respectively. The value of $t_{m}$ which is compared with the same carbon concentration increases with the decrease of $\beta$ value, because the melting rate of scrap decreases and also the heat energy which is consumed as the latent heat of scrap melting decreases. The tendency of the variation of the trajectory of $\left(c_{m}, t_{m}\right)$ on $T-C$ diagram illustrated in 
Fig. 10 is the same as shown in Fig. 9 and the effect of the parameter, $\beta$, on the behavior of the point $\left(c_{m}, t_{m}\right)$, may be considered to be similar to that of $\alpha_{1}$.

\section{Mathematical Model Considering the Melting Process of Scrap}

\section{Theoretical Analysis}

To predict the behaviors of process variables caused by the melting process of scrap fed into LD converter, a mathematical model for the scrap-melting process mentioned above has been interlaced with the model of LD converter previously proposed by the authors. ${ }^{4), 5 \text { ) }}$

Fundamental equations regarding the concentrations of carbon, $C_{1}$, and of silicon, $C_{2}$, in molten steel, mass of silica $\left(\mathrm{SiO}_{2}\right)$, mass of wustite $(\mathrm{FeO})$ and mass of total iron $(\mathrm{T} \cdot \mathrm{Fe})$ in slag, mass of molten steel, $W_{m}$, mass of scrap, $W_{s c}$, and mass of slag, $W_{s}$, and the temperatures of molten steel, $T_{m}$, and of scrap, $T_{s c}$, are derived as follows:

$$
\begin{aligned}
& d\left(W_{m} C_{1}\right) / d \Theta=-\sigma_{1} S-\left(C_{s c} d W_{s c} / d \Theta\right) \cdot U\left(-d W_{s c} / d \Theta\right) \\
& -\left(C_{1} d W_{s c} / d \Theta\right) \cdot U\left(d W_{s c} / d \Theta\right) \\
& d\left(W_{m} C_{2}\right) / d \Theta=-(1 / 2) \sigma_{2} S . \\
& d W_{(2)} / d \Theta=(1 / 2) \sigma_{2} M_{\mathrm{SiO}_{2}} S \\
& d W_{(3)} / d \Theta=\sigma_{3} M_{\mathrm{FeO}} S \\
& d W_{(\mathrm{T} \cdot \mathrm{Fe})} / d \Theta=\left(M_{\mathrm{Fe}} / M_{\mathrm{FeO}}\right) \cdot\left(d W_{(3)} / d \Theta\right) \\
& d W_{m} / d \Theta=-d W_{s c} / d \Theta+\sum_{k=1}^{2}\left(M_{k} W_{m} C_{k}\right) / d \Theta \\
& -d\left\{\left(M_{\mathrm{Fe}} / M_{\mathrm{FeO}}\right) W_{(3)}\right\} / d \Theta \\
& +\left(2 M_{\mathrm{Fe}} / M_{\mathrm{Fe}_{2} \mathrm{O}_{3}}\right) \cdot{ }_{i} W_{\text {ore }} \delta\left(\Theta-{ }_{i} \Theta_{\text {ore }}\right) \\
& d W_{s c} / d \Theta=\left[\alpha_{1}\left(T_{m}-T_{s c}^{\prime}\right)-\alpha_{2}\left(T_{s c}^{\prime}-T_{s c}\right)\right] /\left(-\Delta H_{\mathrm{Fe}}\right) \\
& d W_{s} / d \Theta=d W_{(2)} / d \Theta+d W_{(3)} / d \Theta+d W_{(l)} / d \Theta . \\
& d\left[\left(c_{p s} W_{s}+c_{p m} W_{m}\right) T_{m}\right] / d \Theta \\
& =q_{t}-\alpha_{1}\left(T_{m}-T_{s c}^{\prime}\right) \\
& -\left(c_{p s c} T_{s c} d W_{s c} / d \Theta\right) \cdot U\left(-d W_{s c} / d \Theta\right) \\
& -\left(c_{p m} T_{m} d W_{s c} / d \Theta\right) \cdot U\left(d W_{s c} / d \Theta\right) . \\
& d\left(c_{p s c} W_{s c} T_{s c}\right) / d \Theta \\
& =\alpha_{2}\left(T_{s c}^{\prime}-T_{s c}\right)+\left(c_{p s c} T_{s c} d W_{s c} / d \Theta\right) \cdot U\left(-d W_{s c} / d \Theta\right) \\
& +\left(c_{p m} T_{m} d W_{s c} / d \Theta\right) \cdot U\left(d W_{s c} / d \Theta\right) \text {. }
\end{aligned}
$$

where, the surface temperature of scrap, $\mathcal{T}_{s c}^{\prime}$, can be expressed as Eq. (34) from Eqs. (18), (19), and (20).

$$
\begin{aligned}
T_{s c}^{\prime}= & \left(a+b C_{1}\right) \cdot U\left(d W_{s c} / d \Theta\right)+\left[\beta\left(a+b C_{1}\right)\right. \\
& +\left\{\alpha_{1} b /\left(-\Delta H_{\mathrm{Fe}}\right)\right\} \cdot\left\{\left(\alpha_{2} / \alpha_{1}\right) T_{s c}+T_{m}\right\} \\
& \left.\times\left(C_{1}-C_{s c}\right)\right] /\left[\beta+\left\{\alpha_{1} b /\left(-\Delta H_{\mathrm{Fe}}\right)\right\}\right. \\
& \left.\times\left(1+\alpha_{2} / \alpha_{1}\right)\left(C_{1}-C_{s c}\right)\right] \cdot U\left(-d W_{s c} / d \Theta\right)
\end{aligned}
$$

\section{Calculated Results and Considerations}

Numerical calculations based on the practical operating conditions $^{6)}$ and the adjustable parameters ${ }^{15}$ ) given in Table 2 have been made with the aid of a digital computer (FACOM 230-60).

The results obtained from the numerical calculations and the data obtained by the other investigators ${ }^{6)}$ under the operating conditions given in Table 2 are illustrated in Fig. 11. Although the oxidations of phosphorus and manganese have not been considered in these calculations, it may be found that the calculated results are coincident comparatively with the observed data.

\section{Effects of the Feeding Conditions of Scrap}

\section{Preheated Scrap}

When scrap has been preheated, the sensible heat for melting of scrap decreases, and so the melting process of scrap may be promoted.

Table 2. Data for numerical calculation

$\begin{array}{ll}\text { Diameter of throat } & 26.7 \mathrm{~mm} \dot{\phi} \times 3 \\ \text { Lance height } & 0.7 \mathrm{~m} \\ \text { Back pressure } & 8.6 \mathrm{~atm} \\ \text { Temperature of pig iron } & 1300^{\circ} \mathrm{C} \\ \text { Temperature of scrap } & 30^{\circ} \mathrm{C} \\ \text { Carbon concentration of pig iron } & 4.4 \% *, 4.3 \% * * \\ \text { Silicon concentration of pig iron } & 0.7 \% \\ \text { Mass of pig iron } & 43.2 \mathrm{t} \\ \text { Mass of scrap } & 10.8 \mathrm{t} \\ \text { Mass of ore } & 150 \mathrm{~kg}(7.5,8.5,9.5,10.5,11.5, \\ & 12.5 \mathrm{~min}, \mathrm{respectively}) \\ \text { Mass of lime } & 450 \mathrm{~kg}(0.5,2,3.5,4.5,6.5, \\ & 7.5 \mathrm{~min}, \mathrm{respectively}) \\ \text { Parameter used : } & \\ k_{1}=1 \times 10^{12} \mathrm{~kg}(\mathrm{Fe}) / \mathrm{kgmol}(\mathrm{C}) \cdot \mathrm{sec}, \\ k_{2} / k_{1}=20 \mathrm{kgmol}(\mathrm{C}) / \mathrm{kgmol}(\mathrm{Si}), \\ k_{3} C_{3} / k_{1}=1 \times 10^{-4} \mathrm{kgmol}(\mathrm{C}) / \mathrm{kg}(\mathrm{Fe}), \\ t_{e}=1 \times 10^{-5} \mathrm{sec}, & \\ h_{L}=12 \mathrm{kcal} / \mathrm{m}^{2} \mathrm{sec} \cdot{ }^{\circ} \mathrm{C}, & \\ h_{G}=0.6 \mathrm{kcal} / \mathrm{m}^{2} \cdot \mathrm{sec} \cdot{ }^{\circ} \mathrm{C}, & \\ h_{s c m}=16.54 \mathrm{kcal} / \mathrm{m}^{2} \cdot \mathrm{sec} \cdot{ }^{\circ} \mathrm{C}, & \\ k_{s c m}=2 \times 10^{-4} \mathrm{~m} / \mathrm{sec}, & \\ \alpha_{2} / \alpha_{1}=0.15(-), & \\ A_{s c} / W_{m i}=0.5 \times 10^{-3} \mathrm{~m}^{2} / \mathrm{kg}(\mathrm{Fe}) & \end{array}$

* Adopted for Fig. 11.

** Adopted for Figs. 12 to 14.

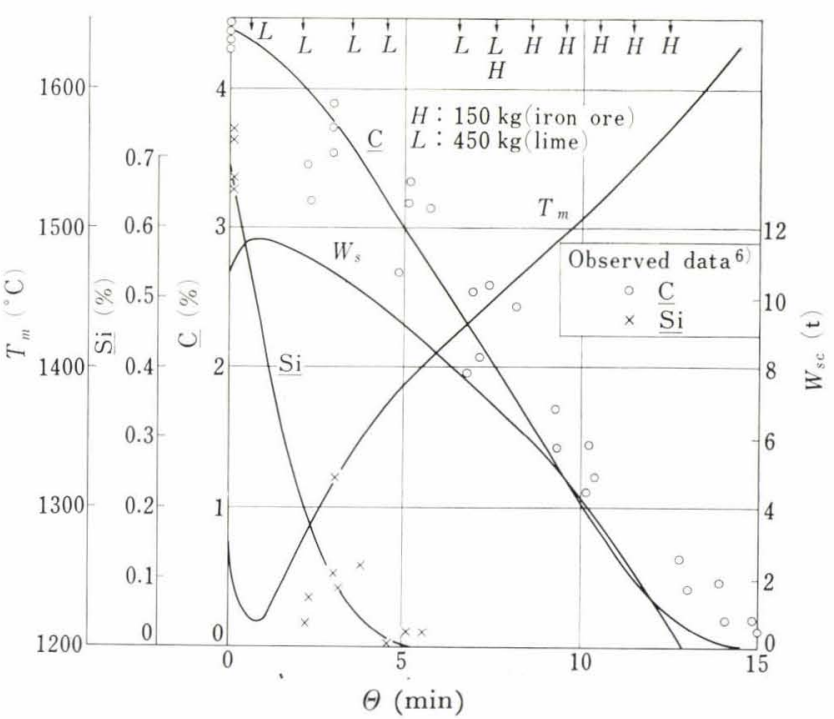

Fig. 11. Calculated results of the transitional variations of process variables in standard process and observed data reported by the other investigators ${ }^{6)}$ 
The results calculated for the cases where the initial temperatures of scrap, $T_{s c i}$, have been assumed to be $30^{\circ}, 500^{\circ}$, and $900^{\circ} \mathrm{C}$, respectively are illustrated in Fig. 12. The solid line in Fig. 12 represents the results calculated for the case of $T_{s c i}=30^{\circ} \mathrm{C}$ where scrap has not been preheated, and the solidification of pig iron on the surface of scrap takes place at the beginning of blowing process.

However, in the cases shown by a dashed and a dot-and-dash lines in Fig. 12 where the preheated scrap has been fed into the converter, the solidification of pig iron does not take place and the melting process of scrap occurs from the beginning of blowing.

The higher the preheated temperature of scrap is, the higher the value of $C_{m}$ becomes at the moment when the scrap fed into the bath has been melted down completely. From these results, it may be considered that the scrap ratio increases in the case where scrap is preheated.

\section{Scrap Ratio}

To find the effects of the values of the scrap ratio on the relations between $C_{m}$ and $T_{m}$, the results calculated for the case of each scrap ratio of 0.15 and 0.25 are shown in Fig. 13.

It may be found from Fig. 13 that the value of $C_{m}$ at the moment when the melting of scrap has been completed decreases with the increase of the scrap ratio, and that the scrap ratio has a considerable effect on the transitional variations of $C_{m}$ and $T_{m}$ during the blowing process.

\section{Carbon Concentration of Scrap}

To evaluate the effects of the carbon concentration of scrap on the relations between $C_{m}$ and $T_{m}$, the results calculated for each case of $0.1 \% \mathrm{C}$ and $4.3 \% \underline{\mathrm{C}}$ are shown in Fig. 14. The melting rate of cold pig iron $(4.3 \% \underline{\mathrm{C}})$ may be determined by the heat transfer and at the early stage of blowing the value of $T_{m}$ decreases remarkably due to the rapid melting.

Furthermore, since the compensation effect relevant to the carbon concentration disappears in the case of feeding cold pig iron, it may be found from Fig. 14 that a large difference in the trajectories of $\left(C_{m}, T_{m}\right)$ exists

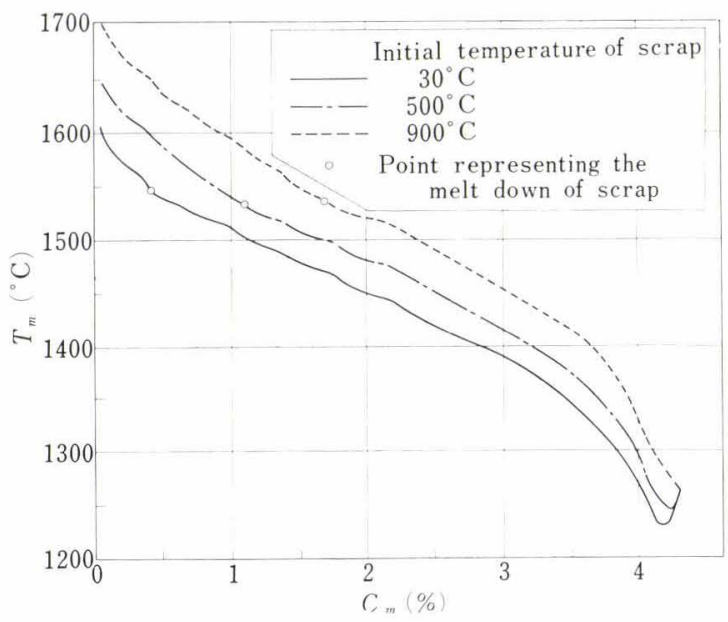

Fig. 12. Calculated results of the relations between $C_{m}$ and $T_{m}$ under the conditions of various initial temperature of scrap $\left(T_{m}-C_{m}\right.$ diagram) between the cases of $4.3 \% \underline{\mathrm{C}}$ and $0.1 \% \underline{\mathrm{C}}$.

\section{Conclusion}

By plotting the empirical data obtained by the other investigators in the practical blowing process on the $T-C$ diagram, it has been found that there are considerable differences between the data obtained in the case where scrap is fed into the converter and those in the case without the feed of scrap.

It has been found from the data in the case with the feed of scrap that the trajectory on the $T-C$ diagram lies near to the liquidus line of the iron-carbon phase diagram during the blowing period except for the beginning. Regarding the system as a lumped parameter one, a mathematical model for the melting process of scrap has been developed.

On the basis of this model, the behaviors of the temperature and the carbon concentration of molten steel on the $T-C$ diagram have been calculated under the conditions with the disturbance of the temperature or the carbon concentration. It has been found from the calculated results that scrap has the effect compensating disturbances in the temperature and the carbon concentration of molten steel.

Furthermore, a mathematical model for the scrap-

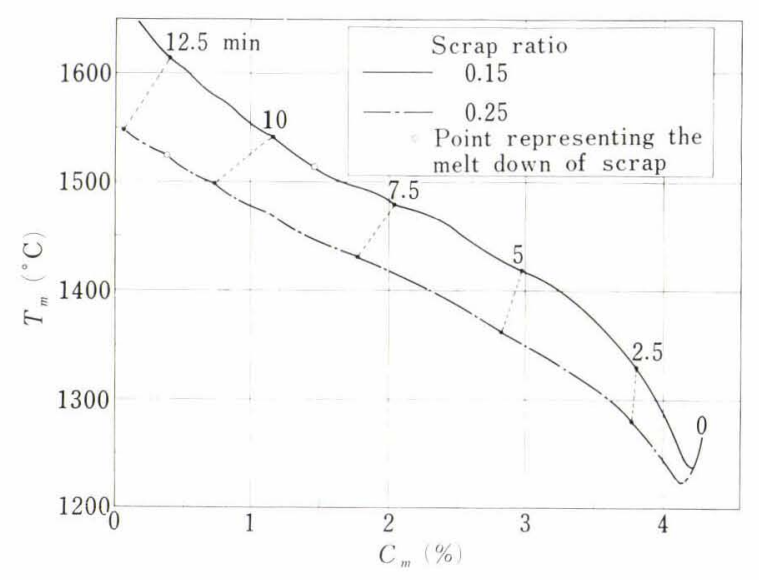

Fig. 13. Calculated results of the relations between $C_{m}$ and $T_{m}$ under the conditions of various scrap ratios

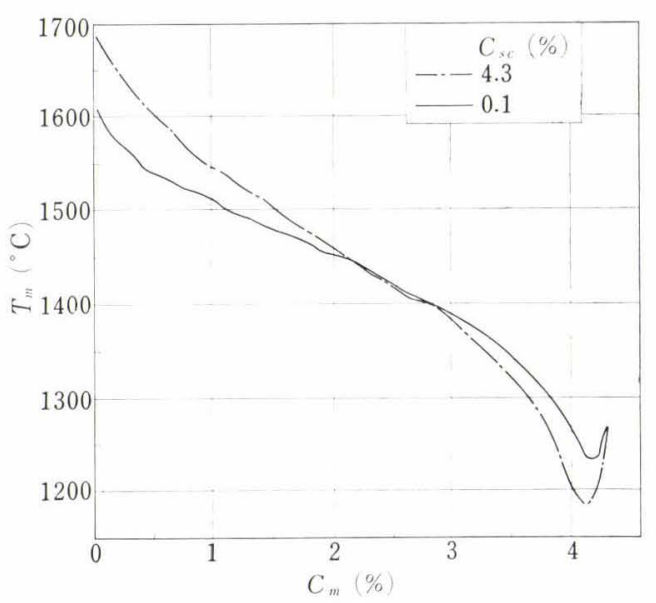

Fig. 14. Calculated results of the relations $C_{m}$ and $T_{m}$, under the conditions of various concentrations of carbon contained in scrap 
melting process has been interlaced with the mathematical model of LD converter previously proposed by the authors, and numerical calculations have been conducted under various operating conditions with the aid of digital computer.

\section{Nomenclature}

$a, b: \quad$ constant in Eq. (1) $\quad\left({ }^{\circ} \mathrm{C}\right),\left({ }^{\circ} \mathrm{C} \cdot \mathrm{kg}(\mathrm{Fe}) / \mathrm{kgmol}\right.$ (C))

C, $C$ : carbon concentration $(\operatorname{kgmol}(\mathrm{C}) / \mathrm{kg}(\mathrm{Fe}))$,

$(\%)$

$C_{j}$ : concentration of $j$-component $(\operatorname{kgmol}(\mathrm{j}) / \mathrm{kg}$ $(\mathrm{Fe}))$

$c$ : non-dimensional carbon concentration, $C / C_{m i}$ $(-)$

$c_{p}: \quad$ specific heat $\left(\mathrm{kcal} / \mathrm{kg} \cdot{ }^{\circ} \mathrm{C}\right)$

$\Delta H_{\mathrm{CO}}, \Delta H_{\mathrm{Fe}}$ : enthalpy changes in decarburization and scrap melting, respectively $(\mathrm{kcal} / \mathrm{kgmol}(\mathrm{C}))$, $(\mathrm{kcal} / \mathrm{kg}(\mathrm{Fe}))$

$-\Delta H_{\mathrm{a} 11}$ : over-all heat of reaction including the decarburization and the oxidation of silicon and iron $(\mathrm{kcal} / \mathrm{kg}(\mathrm{O}))$

$h_{G}, h_{L}$ : heat-transfer coefficients from surface of cavity to gaseous flow and to molten steel, respectively $\left(\mathrm{kcal} / \mathrm{m}^{2} \cdot \mathrm{sec} \cdot{ }^{\circ} \mathrm{C}\right)$

$h_{\text {sem }}$ : heat-transfer coefficient between scrap and molten steel $\left(\mathrm{kcal} / \mathrm{m}^{2} \cdot \mathrm{sec} \cdot{ }^{\circ} \mathrm{C}\right)$

$k_{1}, k_{2}, k_{3}$ : rate constant of decarburization, and those of oxidations of silicon, and of iron, respectively $(\mathrm{kg}(\mathrm{Fe}) / \mathrm{kgmol}(\mathrm{C}) \cdot \mathrm{sec}),(\mathrm{kg}(\mathrm{Fe}) / \mathrm{kgmol}$ $(\mathrm{Si}) \cdot \mathrm{sec}),(\mathrm{kg}(\mathrm{Fe}) / \mathrm{kgmol}(\mathrm{Fe}) \cdot \mathrm{sec})$

$k_{\text {sem }}$ : mass-transfer coefficient of carbon between scrap and molten steel $(\mathrm{m} / \mathrm{sec})$

M: molecular mass $(\mathrm{kg} / \mathrm{kgmol})$

$q_{t}$ : total heat-transfer rate to gas flow (kcal/sec)

$S$ : moles of carbon consumed per unit time in the reaction with oxygen adsorbed into molten steel $(\operatorname{kgmol}(\mathrm{C}) / \mathrm{sec})$

$T, t: \quad$ temperature $\left({ }^{\circ} \mathrm{C}\right), T / T_{m i}(-)$

$U(x):$ step function

$W, w:$ mass $(\mathrm{kg}), W / W_{m i}(-)$

${ }_{i} W_{j}: \quad$ mass of $j$-component charged at $i$-th turn $(\mathrm{kg})$

$\alpha_{1}, \alpha_{2}$ : product of the effective surface area of scrap and the heat-transfer coefficient in metal side and that in scrap side, respectively (kcal/ $\sec \cdot{ }^{\circ} \mathrm{C}$ )

$\beta$ : $\quad$ product of the effective surface area of scrap and the mass-transfer coefficient in metal side $(\mathrm{kg}(\mathrm{Fe}) / \mathrm{sec})$

$\delta(x)$ : delta function

$\Theta, \theta: \quad$ blowing time (sec), $\Theta / \Theta_{t}(-)$

$\Theta_{t}: \quad$ total blowing time (sec)

$\sigma_{1}, \sigma_{2}, \sigma_{3}$ : ratios of oxygen consumed in decarburization, oxidation of silicon and oxidation of iron to total oxygen supplied. (-)

(suffix) 1: C, 2: Si 3: Fe, (2): $\left(\mathrm{SiO}_{2}\right),(3):(\mathrm{FeO}), i$ : at the beginning of blowing time, $m$ : molten steel, ore: iron ore, s: slag, sc: scrap

\section{REFERENCES}

1) R. Jeschar and E. Millies: Arch. Eisenhüttenw., 37 (1966), 283.

2) K. Mori and H. Nomura: Tetsu-to-Hagané, 55 (1969), 347.

3) T. Ariyoshi: Tetsu-to-Hagané, 54 (1968), S 118.

4) S. Asai and I. Muchi: Tetsu-to-Hagané, 55 (1969), 122.

5) S. Asai and I. Muchi: Trans. ISIJ, 10 (1970), 250.

6) Nippon Kokan K. K.: Report presented on the 41st Meeting of Steelmaking Division of The Iron and Steel Institute of Japan, Nov., 1968, No. 41-18.

7) S. Dazai: Paper presented at the 19th Committee of Japan Socicty for the Promotion of Science, (1967, Oct.)

8) K. Narita, A. Tomita, S. Koyama, T. Ito, and Y. Hirooka: Tetsu-to-Hagané, 55 (1969), 59.

9) T. Ōya, I. Furugaki, and A. Minami: Tetsu-to-Hagané, 51 (1965), 748.

10) R. Imai, K. Kawakami, S. Miyoshi, and S. Jinbo: Nippon Kokan Technical Report, 39 (1970), 19.

11) K. Nikami, K. Matsuda, T. Koyano, and T. Yasui: Tetsuto-Hagané, 52 (1966), 1491.

12) K. Grünberg, W. Schleicher, and R. Kung: Stahl u. Eisen, 80 (1960), 277.

13) K. Takeda: Tetsu-to-Hagané, 48 (1962), 1085.

14) E. Z. Freidenzon, V. G. Udovenko, Yu. V. Torshilov, G. M. Kompaniets, M. A. Tretyakov, V. M. Baranov, D. F. Nagovitsin, S. A. Donski, and A. I. Pastukhov: Stal in English, June (1965), 469.

15) S. Asai and I. Muchi: Tetsu-to-Hagané, 57 (1971), (in print). 